\title{
Attitudes and beliefs of the French public about schizophrenia and major depression: results from a vignette-based population survey
}

\author{
Matthias C Angermeyer ${ }^{1,2}$, Aurélie Millier $^{3^{*}}$, Cécile Rémuzat ${ }^{3}$, Tarek Refai ${ }^{4}$ and Mondher Toumi ${ }^{5}$
}

\begin{abstract}
Background: In their study 'Mental Health in the General Population: Images and Realities' Jean-Luc Roelandt et al. found a huge divide between the French public's conceptualizations of insanity and depression. The study aims to examine whether such differences can be replicated using modern operationalized diagnostic criteria for schizophrenia and major depressive disorder.
\end{abstract}

Methods: In 2012, an online survey was conducted using a representative sample drawn from the adult French population ( $N=1600$ ). After presentation of a case-vignette depicting a person with either schizophrenia or major depressive disorder a fully structured interview was carried out.

Results: Despite some similarities marked differences between both disorders emerge regarding beliefs and attitudes. While respondents presented with the schizophrenia vignette more frequently defined symptoms as the expression of an illness with a stronger biological component and a less favorable prognosis, demanding psychiatric treatment, respondents presented with the depression vignette considered the occurrence of symptoms more frequently as the consequence of current psychosocial stress, benefitting not only from established but also from alternative treatments. People with schizophrenia were more frequently perceived as unpredictable and dangerous, there was a stronger need to separate one-self from them, they were more frequently met with fear and less frequently reacted to with pro-social feelings, and they also faced more rejection.

Conclusions: The French public draws a clear line between schizophrenia and major depressive disorder. This applies equally to beliefs about both disorders and to attitudes towards the persons afflicted. There is a need for interventions trying to reduce existing misconceptions in order to improve the care of patients.

\section{Background}

In their ground-breaking study 'Mental Health in the General Population: Images and Realities' Jean-Luc Roelandt et al. [1,2] provided a comprehensive description of how mental illness is perceived by the general public in France. Using the concept of social representations as a theoretical framework, they explored the public's notion of the 'insane', the 'mentally ill', and the 'depressive'. They found that the public draws a clear line between the representation of the 'insane' on one hand and the 'depressive' on the other hand. While insane people were described as abnormal, irresponsible, socially excluded, far from being curable, and to be treated against

\footnotetext{
*Correspondence: ami@creativ-ceutical.com

${ }^{3}$ Creativ-Ceutical, Paris, France

Full list of author information is available at the end of the article
}

their will by psychotropic drugs and psychiatric hospitalization, depressive people were perceived as more familiar, suffering, and curable. Moreover, over $75 \%$ of respondents associated the words 'insane' with violent and dangerous behaviors while the term 'depressive' was associated with sadness, isolation, and suicide.

Stimulated by Roelandt et al.'s work we set out to also investigate the French public's perception of mental illness, this time studying it from a different theoretical and methodological angle. Instead of employing words used in everyday language to denote mental illness ('insane', 'depressive') as stimulus, we presented the interviewees with vignettes depicting a person suffering from symptoms of either schizophrenia (which was assumed to correspond most closely to what is understood by the term 'insane') or major depressive disorder. Thus, while
Ciomed Central

(c) 2013 Angermeyer et al.; licensee BioMed Central Ltd. This is an open access article distributed under the terms of the Creative Commons Attribution License (http://creativecommons.org/licenses/by/2.0), which permits unrestricted use, distribution, and reproduction in any medium, provided the original work is properly cited. 
in Roelandt et al.'s study the public's associations to mundane labels were assessed, in our study reactions to descriptions of pathological behavior fulfilling diagnostic criteria used in psychiatry were examined.

Vignette-based studies conducted in other countries indicate that despite some similarities there are marked differences between the two disorders as concerns public beliefs and attitudes. Schizophrenia was found to be seen as an illness with a strong biological component and a rather unfavorable prognosis, demanding psychiatric treatment. Major depressive disorder, in contrast, was considered more as a consequence of the exposure to psycho-social stress, benefitting mostly from psychotherapy and alternative treatments. Moreover, people with schizophrenia were more frequently perceived as unpredictable and dangerous. They were more frequently met with fear and less frequently reacted to with pro-social feelings. People with schizophrenia also did face more rejection than those with depression [3-5].

In this paper, we will present findings on the public's knowledge and beliefs about schizophrenia and major depressive disorder as well as on public attitudes towards people suffering from these disorders. For the study of the public's knowledge and beliefs, Anthony Jorm's [6] concept of mental health literacy will serve as the theoretical framework. Mental health literacy refers to 'knowledge and beliefs about mental disorders which aid their recognition, management or prevention' and includes 'the ability to recognize specific disorders; knowing how to seek mental health information; knowledge of risk factors and causes, of self-treatments, and of professional help available' [7]. This knowledge may play an important role in seeking help for mental health problems [8].

For the study of attitudes we used as the theoretical framework the stigma concept developed by Bruce Link and Jo Phelan $[9,10]$. According to the authors, stigma exists when the following interrelated components converge: (1) people distinguish and label human differences; (2) dominant cultural beliefs link labeled persons to undesirable characteristics that form the stereotype; (3) labeled persons are seen as an out-group, as 'them' and not 'us'; (4) stereotyping and separating evoke negative emotions; and (5) labeled persons experience loss of status and discrimination. One form of discrimination is the overt discrimination directed towards a person with a mental disorder, such as rejecting their job application or refusing to rent them an apartment. In research, this is most frequently measured by desire for social distance.

The aim of our study is to examine to what extent Roelandt et al.'s findings can be replicated using casevignettes with the description of mental disorders fulfilling modern operationalized diagnostic criteria. We want explore potential differences in the French public's knowledge and beliefs about schizophrenia and major depressive disorder. More specifically, we want to determine what differences exist between both disorders with regard to recognition, causal attributions, expected prognosis, help-seeking preferences, and treatment beliefs. Moreover, we want to examine to what extent public attitudes towards people affected by these disorders differ and what differences exist with regard to stereotypes, separation of 'us' from 'them', emotional reactions, and desire for social distance.

\section{Methods}

\section{Survey}

Persons aged 16-65 years old, of French nationality, were drawn from an established market research panel. The panel is recruited and managed under the highest standards ('MRA Verified' seal, adhering to CASRO and ESOMAR guidelines). Persons were contacted by email and invited to participate in an on-line survey between January and March 2012. If a person did not respond to the initial contact, he or she was contacted again three days later. Recruitment continued until 1600 interviews were obtained. Participants were aware that their responses would be used for scientific research, specifically commissioned by the authors. To ensure that the sample was representative of the general adult population of France, sampling was stratified for place of residence, gender, age, and family status. In total, 1,600 persons were interviewed. The socio-demographic characteristics of the sample reflect fairly well the socio-demographic composition of the general population in France [11]: 50\% were men (France: $50.6 \%$ ); $17.5 \%$ of respondents were $16-24$ years old, 20.2\% 25-34 years old, 22.1\% 35-44 years old, $21.3 \% 45-54$ years old, and 18.9\% 55-65 years old (France: $17.1 \%, 19.1 \%, 20.9 \%, 21.1 \%$, and $21.7 \%$, respectively). $43.1 \%$ of respondents were single (France: $45.8 \%$ ). The educational level of respondents was as follows: $17.3 \%$ CAP/BEP, $21.7 \%$ bachelor, and $61.0 \%$ superior or other (France: $23.4 \%, 17.1 \%$, and 59.5\%, respectively). Informed consent was considered to have been given when individuals agreed to complete the interview.

\section{Interview}

The fully-structured interview had originally been developed in Germany and had been successfully employed there in several surveys $[4,12]$. For use in this study, it was translated into French following the guidelines of WHO [13]. At the beginning of the interview respondents were presented with a vignette of a diagnostically unlabeled psychiatric case history, depicting a case of either schizophrenia or major depressive disorder. The symptoms described in the vignettes that had originally been prepared for the German surveys fulfilled the criteria of DSM-III-R for the respective disorder [14]. Each vignette had been independently rated by five experts on 
psychopathology masked to actual diagnosis, providing confirmation of the correct diagnosis for each case history. In order to be able to compare our findings with those from Germany we decided to use the same vignettes. The sex of the individual presented in the vignettes was randomly varied. Respondents were randomly allocated to receive either the vignette depicting schizophrenia or the vignette depicting major depressive disorder.

\section{Measures of beliefs about schizophrenia and major depressive disorder}

Following the presentation of the vignette, respondents were asked whether the problem depicted in the vignette represented in their eyes 'a mental illness in the medical sense' or not. Next, respondents' causal attributions were elicited with a list of twelve possible causes, each of which had to be rated on a five-point Likert scale anchored with $1=$ 'certainly a cause' and $5=$ 'certainly not a cause'. Three items each were referencing either current psychosocial stress ('stressful life-event', 'workrelated stress', 'problems with partner and family'), childhood adversities ('grown up in a broken home', 'lack of parental affection', 'childhood sexual abuse'), biogenetic causes ('chemical imbalance in the brain', 'brain disease', 'heredity'), and intra-psychic causes ('immoral life style', 'weak will', 'unconscious conflict'). Respondents who endorsed the two points on either side of the mid-point of the scale ('undecided') were grouped together into the categories 'a cause' or 'not a cause', respectively.

With the help of the following items the prognosis anticipated by respondents was assessed: 'The person will never get over it completely'; 'The person will never be able to make important decisions alone'; 'The person is going to decline a priori'; 'The person will never be able to perform regular professional obligations'. The items had to be rated on a five-point Likert scale anchored with $1=$ 'totally agree' and 5 = 'totally disagree'. Respondents who endorsed the two points on either side of the mid-point of the scale ('undecided') were grouped together into the categories 'agree' or 'disagree', respectively.

Considering attitudes towards treatment, a distinction was made between health care providers and treatment methods. Help-seeking recommendations were assessed using a catalogue of the following sources of help: psychiatrist, psychotherapist, general practitioner, health practitioner, priest, self-help group, the Internet, and confidant. The respondents were asked to indicate their endorsement or rejection of each source of help, using a five-point Likert scale ranging from 'would strongly recommend' to 'would not recommend at all' plus a 'don't know' category. Respondents who endorsed the two points on either side of the mid-point of the scale ('undecided') were grouped together into the categories 'recommend' or 'advise against', respectively.
Using a five-point scale ranging from 'would strongly recommend' to 'would not recommend at all' (plus 'don't know') respondents were asked to provide their treatment recommendations, offering a list of six different treatment methods, three representing established forms of psychiatric treatment (psychotropic medication, psychotherapy, relaxations techniques) and three 'alternative' treatment modalities (natural remedies, mediation, acupuncture). The response categories were combined in the same way as described for help-seeking recommendations.

\section{Measure of attitudes towards people with mental disorders}

After the assessment of respondents' mental health literacy, questions on their attitudes towards the person depicted in the vignette were asked. According to Hayward and Bright [15], the four most important stereotypes about mental illness are that people with mental disorders are unpredictable, that they are dangerous, that they are responsible for their illness, and that mental illnesses are hard to treat. Agreement or disagreement with these stereotypes was recorded with the help of a five-point Likert scale, anchored with 1 = 'fully agree' and ' 5 ' 'totally disagree'.

The tendency to separate oneself from the person in the vignette was measured by means of the items 'This person is different from others' and 'Basically we are all sometimes like this person. It's just a question how pronounced this state is'. Agreement or disagreement with these stereotypes was recorded with the help of a five-point Likert scale, anchored with 1 = 'fully agree' and '5' 'totally disagree'.

Emotional reactions to the person described in the vignette were assessed by means of nine five-point Likertscaled items, anchored with 1 = 'applies completely' and 5 = 'does not apply at all', representing the main three dimensions fear, anger, and pro-social reactions: 'I feel the need to help him/her', 'I feel pity', 'I feel uncomfortable', 'He/she makes me feel insecure', 'He/she scares me', 'I feel sympathy for him/her', 'I feel annoyed by him/her', 'I react angrily', 'I am amused by something like that'. Respondents who endorsed the two points on either side of the midpoint of the scale ('undecided') were grouped together to the categories 'agree', or 'disagree', respectively [16].

For the assessment of respondents' desire for social distance we used the scale developed by Link et al [17]. This scale encompasses the following social situations: rent a room, work together, have as a neighbor, let take care of a little child, have marry into family, introduce to friends, recommend for a job. With the help of a fivepoint Likert scale respondents could indicate to what extent they were willing or unwilling to engage in the proposed relationships. Respondents who endorsed the two points on either side of the mid-point of the scale ('undecided') were grouped together into the categories 'accept', or 'reject', respectively. 


\section{Statistical analysis}

In order to examine whether respondents reacted differently with regard to the schizophrenia vignette and the depression vignette, we calculated separate multinomial logit regressions for each item. To adjust for potential differences between samples for the influence of demographic factors, the regression analyses controlled for respondents' gender, age, and educational attainment. To illustrate the magnitude of differences between the subsamples presented with the schizophrenia or the depression vignette, discrete probability changes were calculated for all items and each response category with control variables held at their means for the whole sample. A discrete change coefficient is the difference in the predicted probability of a given outcome between both subsamples; it serves as an indicator of the effect size of the change. Ninety-five percent confidence intervals were computed with the delta method. The calculation of probability changes was carried out using SAS 9.3 [18]. To make adjusted predictions comparable to unadjusted survey results, probabilities and discrete changes are multiplied by 100 and can be read as percentage of respondents choosing any answer category. Tables 1, 2, 3, 4, 5, 6, 7, 8 and 9 show, separately for schizophrenia and major depressive disorder, the raw percentage and the predicted probability for each item/ answer category plus the difference in probabilities between both disorders and the confidence interval for this difference.

\section{Results}

Beliefs about schizophrenia and major depressive disorder Recognition

With schizophrenia, the vast majority of respondents (78\%) endorsed the view that the person depicted in the vignette suffers from an illness in the medical sense, whereas with major depressive disorder this view was shared by only $58 \%$, while $21 \%$ each answered in the negative or could not give an answer (Table 1).

\section{Causal beliefs}

In Table 2 the French public's beliefs about the causes of the two mental disorders in question are reported. Biogenetic factors were twice as likely to be endorsed as a cause of schizophrenia than as a cause of major depressive disorder. With depression, the majority disagreed

Table 1 Labeling of schizophrenia and major depression

\begin{tabular}{|c|c|c|c|c|c|c|}
\hline & \multicolumn{2}{|c|}{ Schizophrenia } & \multicolumn{2}{|c|}{ Major depression } & \multirow[b]{2}{*}{ Change } & \multirow[b]{2}{*}{$95 \% \mathrm{Cl}$} \\
\hline & Raw \% & $\overline{\text { Adj. } \%}$ & Raw \% & Adj. \% & & \\
\hline Mental illness & 78.0 & 78.8 & 58.1 & 59.3 & -19.5 & $\overline{[-23.9 ;-15.0]}$ \\
\hline No mental illness & 7.6 & 7.4 & 20.6 & 20.1 & 12.7 & {$[9.4 ; 16.0]$} \\
\hline Don't know & 14.4 & 13.8 & 21.2 & 20.5 & 6.7 & {$[0.8 ; 12.7]$} \\
\hline
\end{tabular}

with this etiological explanation. In contrast, psychosocial stress was considered a cause of depression by four out five respondents, while with schizophrenia the percentage was markedly lower. Smaller or no differences between both disorders were observed with regard to childhood adversities. The same applies to personality factors, except for weak will which was made responsible considerably more frequently when the schizophrenia vignette was presented. In case of schizophrenia, 'negative life events' were chosen most frequently as a cause (65\%), followed by 'unconscious conflict' (53\%) and 'disturbance of brain metabolism' (51\%). The most frequently endorsed causes of depression were the three factors representing current stress (negative life events, stress at work, and troubles in family/partnership).

\section{Anticipated prognosis}

In general, respondents were rather optimistic concerning the prognosis of both disorders. However, this tendency was less pronounced with schizophrenia where markedly fewer respondents explicitly disagreed with statements positing a poor course and where more respondents remained undecided or agreed with them (Table 3 ).

\section{Help-seeking recommendations}

As shown in Table 4, among the professional helpers proposed, respondents presented with the schizophrenia vignette recommended most frequently turning to a psychiatrist (81\%), followed by psychotherapists (77\%), and general practitioners (75\%). As concerns major depressive disorder, the order was reversed, with general practitioners being more frequently recommended (83\%) than psychotherapists (68\%) and psychiatrists (59\%). In case of major depression, turning to a practitioner of complementary medicine or making a health cure in a spa was less frequently advised against and informal selfhelp or asking a confidant for help was more frequently recommended. There were no differences between both disorders concerning seeking help from a priest, joining a self-help group, or visiting the Internet.

\section{Treatment recommendations}

Psychotherapy was the uncontested favorite for the treatment of both schizophrenia and major depressive disorder. As concerns schizophrenia, psychotropic medication came next. As concerns depression, medication was less likely to be recommended than all other treatment options; while psychotropic medication was endorsed by only $20 \%$ of the respondents, relaxation techniques, meditation/yoga, natural remedies, or acupuncture were endorsed by $32 \%$ - $42 \%$. More respondents recommended medication for the treatment of schizophrenia than advised against it, with depression the reverse was found (Table 5). 
Table 2 Causal beliefs regarding schizophrenia and major depression

\begin{tabular}{|c|c|c|c|c|c|c|c|}
\hline & & \multicolumn{2}{|c|}{ Schizophrenia } & \multicolumn{2}{|c|}{ Major depression } & \multirow[b]{2}{*}{ Change } & \multirow[b]{2}{*}{$95 \% \mathrm{Cl}$} \\
\hline & & Raw \% & Adj. $\%$ & Raw \% & Adj. $\%$ & & \\
\hline & Agree & 45.4 & 45.0 & 17.0 & 16.6 & -28.4 & {$[-32.9 ;-23.9]$} \\
\hline \multirow[t]{3}{*}{ Brain disease } & Undecided & 25.2 & 24.9 & 19.9 & 19.3 & -5.6 & {$[-9.7 ;-1.4]$} \\
\hline & Disagree & 29.4 & 30.1 & 63.1 & 64.0 & 33.9 & {$[30.0 ; 37.8]$} \\
\hline & Agree & 26.2 & 24.0 & 11.4 & 10.2 & -13.8 & {$[-17.8 ;-9.9]$} \\
\hline \multirow[t]{3}{*}{ Hereditary factors } & Undecided & 23.4 & 23.8 & 17.6 & 17.5 & -6.3 & {$[-10.4 ;-2.3]$} \\
\hline & Disagree & 50.4 & 52.1 & 71.0 & 72.4 & 20.3 & {$[16.5 ; 23.9]$} \\
\hline & Agree & 50.9 & 51.7 & 24.0 & 24.2 & -27.5 & {$[-32.2 ;-22.8]$} \\
\hline \multirow[t]{3}{*}{ Disturbance of brain metabolism } & Undecided & 25.2 & 23.6 & 24.5 & 22.6 & -1.0 & {$[-5.2 ; 3.1]$} \\
\hline & Disagree & 23.9 & 24.7 & 51.5 & 53.3 & 28.6 & {$[24.1 ; 33.1]$} \\
\hline & Agree & 43.5 & 44.2 & 78.1 & 78.4 & 34.2 & {$[29.6 ; 38.9]$} \\
\hline \multirow[t]{3}{*}{ Troubles in family/ partnership } & Undecided & 30.4 & 31.1 & 15.3 & 15.4 & -15.7 & {$[-20.0 ;-11.3]$} \\
\hline & Disagree & 26.1 & 24.7 & 6.6 & 6.1 & -18.6 & {$[-20.6 ;-16.5]$} \\
\hline & Agree & 64.9 & 66.0 & 79.6 & 80.5 & 14.5 & {$[10.1 ; 18.8]$} \\
\hline \multirow[t]{3}{*}{ Negative life events } & Undecided & 21.4 & 20.6 & 12.4 & 11.7 & -8.9 & {$[-12.5 ;-5.2]$} \\
\hline & Disagree & 13.7 & 13.5 & 8.0 & 7.8 & -5.7 & {$[-16.0 ;-1.7]$} \\
\hline & Agree & 47.0 & 49.3 & 79.7 & 81.6 & 32.3 & {$[26.3 ; 38.2]$} \\
\hline \multirow[t]{3}{*}{ Stress at work } & Undecided & 28.5 & 25.8 & 12.3 & 10.6 & -15.2 & {$[-19.7 ;-10.7]$} \\
\hline & Disagree & 24.5 & 24.9 & 8.0 & 7.8 & -17.1 & {$[-19.1 ;-14.9]$} \\
\hline & Agree & 21.9 & 20.1 & 17.3 & 15.6 & -4.5 & {$[-8.1 ;-0.8]$} \\
\hline \multirow[t]{3}{*}{ Broken home } & Undecided & 27.0 & 26.1 & 21.1 & 20.0 & -6.1 & {$[-10.1 ;-2.0]$} \\
\hline & Disagree & 51.1 & 53.8 & 61.6 & 64.4 & 10.6 & {$[6.6 ; 14.5]$} \\
\hline & Agree & 24.4 & 24.4 & 24.0 & 24.2 & -0.2 & {$[-4.5 ; 4.0]$} \\
\hline \multirow[t]{3}{*}{ Lack of parental affection } & Undecided & 32.6 & 33.1 & 29.5 & 29.8 & -3.3 & {$[-7.9 ; 1.2]$} \\
\hline & Disagree & 43.0 & 42.4 & 46.5 & 46.1 & 3.7 & {$[-0.4 ; 7.7]$} \\
\hline & Agree & 24.4 & 24.2 & 24.5 & 24.3 & 0.1 & {$[-4.1 ; 4.4]$} \\
\hline \multirow[t]{3}{*}{ Sexual abuse in childhood } & Undecided & 32.6 & 32.8 & 23.2 & 23.5 & -9.3 & {$[-13.7 ;-4.9]$} \\
\hline & Disagree & 43.0 & 43.0 & 52.3 & 52.1 & 9.1 & {$[5.1 ; 13.2]$} \\
\hline & Agree & 15.1 & 12.3 & 13.0 & 10.4 & -1.9 & {$[-4.8 ; 1.0]$} \\
\hline \multirow[t]{3}{*}{ Immoral life style } & Undecided & 18.9 & 19.3 & 19.5 & 19.7 & 0.4 & {$[-3.5 ; 4.4]$} \\
\hline & Disagree & 66.0 & 68.4 & 67.5 & 69.9 & 1.5 & {$[-2.3 ; 5.3]$} \\
\hline & Agree & 34.5 & 32.8 & 24.1 & 22.6 & -10.2 & {$[-14.6 ;-5.9]$} \\
\hline \multirow[t]{3}{*}{ Weak will } & Undecided & 23.0 & 23.6 & 26.5 & 26.7 & 3.1 & {$[-1.2 ; 7.4]$} \\
\hline & Disagree & 42.5 & 43.5 & 49.4 & 50.7 & 7.2 & {$[3.0 ; 11.3]$} \\
\hline & Agree & 53.4 & 54.1 & 51.5 & 52.2 & -1.9 & {$[-6.8 ; 3.0]$} \\
\hline \multirow[t]{2}{*}{ Unconscious conflict } & Undecided & 27.0 & 25.3 & 27.6 & 26.0 & 0.7 & {$[-3.6 ; 4.8]$} \\
\hline & Disagree & 19.6 & 20.6 & 20.9 & 21.8 & 1.2 & {$[-4.3 ; 6.7]$} \\
\hline
\end{tabular}

\section{Attitudes towards people with schizophrenia and major depressive disorder \\ Stereotypes}

Among the four stereotypes, the perception that the person depicted in the vignette is unpredictable was most frequently endorsed, followed by the perception of dangerousness. Both were twice as frequently associated with schizophrenia ( $73 \%$ and $34 \%$, respectively) than with major depressive disorder (36\% and 14\%, respectively). The remaining two stereotypes, namely that the person is responsible for his/her condition and that the condition is hard to treat, were shared each on their own by less than ten percent of respondents. This applied equally to schizophrenia and major depressive disorder (Table 6). 
Table 3 Expected prognosis of schizophrenia and major depression

\begin{tabular}{|c|c|c|c|c|c|c|c|}
\hline & & \multicolumn{2}{|c|}{ Schizophrenia } & \multicolumn{2}{|c|}{ Major depression } & \multirow[b]{2}{*}{ Change } & \multirow[b]{2}{*}{$95 \% \mathrm{Cl}$} \\
\hline & & Raw \% & Adj. \% & Raw \% & Adj. \% & & \\
\hline \multirow{3}{*}{ The person will never get over it completely } & Agree & 26.0 & 25.3 & 17.9 & 17.2 & -8.1 & {$[-12.1 ;-4.1]$} \\
\hline & Undecided & 33.4 & 34.1 & 22.0 & 22.4 & -11.7 & {$[-16.2 ;-7.2]$} \\
\hline & Disagree & 40.6 & 40.7 & 60.1 & 60.5 & 19.8 & {$[15.9 ; 23.7]$} \\
\hline \multirow{3}{*}{ The person will never be able to make important decisions alone } & Agree & 17.6 & 17.1 & 8.9 & 8.3 & -8.8 & {$[-12.2 ;-5.5]$} \\
\hline & Undecided & 33.5 & 33.6 & 15.7 & 15.3 & -18.3 & {$[-22.5 ;-13.9]$} \\
\hline & Disagree & 48.9 & 49.3 & 75.4 & 76.4 & 27.1 & {$[23.7 ; 30.5]$} \\
\hline \multirow{3}{*}{ The person will never be able to perform regular professional obligations } & Agree & 18.1 & 17.3 & 6.6 & 6.0 & -11.3 & {$[-14.7 ;-7.9]$} \\
\hline & Undecided & 31.6 & 29.9 & 17.5 & 15.8 & -14.1 & {$[-18.3 ;-10.0]$} \\
\hline & Disagree & 50.3 & 52.8 & 75.9 & 78.2 & 25.4 & {$[22.1 ; 28.8]$} \\
\hline \multirow{3}{*}{ The person will always be dependent on others' help } & Agree & 12.4 & 11.4 & 6.1 & 5.5 & -5.9 & {$[-8.8 ;-3.0]$} \\
\hline & Undecided & 35.6 & 36.2 & 19.9 & 19.8 & -16.4 & {$[-20.8 ;-11.8]$} \\
\hline & Disagree & 52.0 & 52.5 & 74.0 & 74.7 & 22.2 & {$[18.7 ; 25.7]$} \\
\hline
\end{tabular}

\section{Separation of 'us' from 'them'}

As shown in Table 7, respondents reacted quite differently to the two vignettes. In the case of major depressive disorder, the tendency to separate oneself from the person in the vignette was much less pronounced. As compared to schizophrenia, respondents disagreed over twice as frequently with the statement that 'the person is different from others' (64\% vs. 29\%), and agreed over twice as frequently with the statement that 'basically we are all sometimes like this person' and that 'it is only a question how pronounced this state is'.

\section{Emotional reactions}

In Table 8, the emotional reactions of respondents to persons with schizophrenia or major depressive disorder are presented. In general, respondents reacted most frequently with pro-social feelings (need to help, pity, sympathy), followed by fear and related feelings (uncomfortable, insecure), whereas feelings of anger, annoyance, and amusement were elicited only rarely. However, the schizophrenia vignette evoked markedly more fear than the depression vignette. While, for instance, $58 \%$ of respondents felt uncomfortable with the person displaying symptoms of schizophrenia, with major depressive disorder the same feeling was expressed by only $35 \%$. In contrast, more prosocial feelings were expressed when respondents were presented with the depression vignette, although the difference between both disorders here was less pronounced. As concerns feelings of anger, annoyance, or amusement, no differences existed between both disorders.

\section{Desire for social distance}

As shown in Table 9, across all seven social relationships, respondents distanced themselves more strongly from the person with symptoms of schizophrenia than from the person with symptoms of major depressive disorder. Except for the most distant relationships (colleague at work, neighbor, introducing to friends), where a considerable proportion did accept the person with schizophrenia or was at least undecided in this regard, over half of respondents rejected him or her in closer relationships. With the depressive person the amount of rejection equaled that of indecisiveness. The vast majority of respondents were opposed to letting the person take care of children no matter which vignette had been presented.

\section{Discussion}

Beliefs about schizophrenia and major depressive disorder A clear pattern emerges from our findings: Schizophrenic symptoms are defined by the vast majority of respondents as expression of mental illness, caused by biogenetic factors and current stress. In contrast, depressive symptoms are less unanimously defined as mental illness, and current stress plays here a dominant causal role. The prognosis of major depressive disorder appears more favorable than that of schizophrenia. In the eyes of the public, psychiatrists represent the most appropriate helping source for people suffering from schizophrenic symptoms, and, apart from psychotherapy, medication is recommended most frequently for treatment. For depressive symptoms, general practitioners are considered most frequently as a source for help; taking a health cure or seeing a practitioner in complementary medicine are less likely to be rejected; apart from formal help, there is also a strong emphasis on self-help and social support. In the eyes of the public, relaxation techniques and 'alternative' methods are better suited for the treatment of major depression than psychotropic medication. Thus, although there exists a certain overlap between both disorders, the French public seems to draw a clear line 
Table 4 Help-seeking recommendations for schizophrenia and major depression

\begin{tabular}{|c|c|c|c|c|c|c|c|}
\hline & & \multicolumn{2}{|c|}{ Schizophrenia } & \multicolumn{2}{|c|}{ Major depression } & \multirow[b]{2}{*}{ Change } & \multirow[b]{2}{*}{$95 \% \mathrm{Cl}$} \\
\hline & & Raw \% & Adj. $\%$ & Raw \% & Adj. \% & & \\
\hline \multirow{4}{*}{ Psychiatrist } & Agree & 81.0 & 82.0 & 58.6 & 60.5 & -21.5 & {$[-34.4 ;-8.7]$} \\
\hline & Undecided & 8.5 & 7.7 & 19.7 & 18.1 & 10.4 & {$[7.7 ; 13.2]$} \\
\hline & Disagree & 6.6 & 6.4 & 17.3 & 16.9 & 10.5 & {$[7.9 ; 13.2]$} \\
\hline & Don't know & 3.0 & 3.9 & 4.4 & 4.5 & 0.6 & {$[0.0 ; 1.2]$} \\
\hline \multirow{4}{*}{ Psychotherapist } & Agree & 76.8 & 78.1 & 68.2 & 70.0 & -8.1 & {$[-22.1 ; 5.8]$} \\
\hline & Undecided & 12.4 & 11.7 & 18.0 & 17.1 & 5.4 & {$[3.2 ; 7.6]$} \\
\hline & Disagree & 7.2 & 6.8 & 9.8 & 9.2 & 2.4 & {$[0.8 ; 4.0]$} \\
\hline & Don't know & 3.6 & 3.4 & 4.0 & 3.7 & 0.3 & {$[-0.2 ; 0.8]$} \\
\hline \multirow{4}{*}{ General practitioner } & Agree & 74.9 & 76.8 & 82.7 & 83.8 & 7.0 & {$[-15.9 ; 29.9]$} \\
\hline & Undecided & 13.4 & 13.4 & 9.8 & 9.6 & -3.8 & {$[-42.4 ; 34.8]$} \\
\hline & Disagree & 8.9 & 9.2 & 6.3 & 6.3 & -2.9 & {$[-25.0 ; 19.3]$} \\
\hline & Don't know & 2.9 & 0.6 & 1.2 & 0.3 & -0.3 & {$[-6.6 ; 5.9]$} \\
\hline \multirow{4}{*}{ Practitioner of complementary medicine } & Agree & 17.1 & 14.4 & 23.9 & 20.6 & 6.2 & {$[-3.0 ; 15.5]$} \\
\hline & Undecided & 19.2 & 18.1 & 23.7 & 22.8 & 4.7 & {$[-1.0 ; 10.4]$} \\
\hline & Disagree & 51.1 & 55.0 & 41.3 & 45.2 & -9.8 & {$[-17.3 ;-2.3]$} \\
\hline & Don't know & 12.6 & 12.5 & 11.1 & 11.3 & -1.2 & {$[-2.5 ; 0.3]$} \\
\hline \multirow{4}{*}{ Pastor/priest } & Agree & 9.5 & 9.3 & 13.2 & 12.9 & 3.6 & {$[-9.9 ; 17.0]$} \\
\hline & Undecided & 17.7 & 17.4 & 18.5 & 18.1 & 0.7 & {$[-18.1 ; 19.6]$} \\
\hline & Disagree & 55.8 & 57.1 & 53.5 & 54.9 & -2.2 & {$[-9.9 ; 5.6]$} \\
\hline & Don't know & 17.0 & 16.2 & 14.8 & 14.1 & -2.1 & {$[-3.5 ;-0.8]$} \\
\hline \multirow{4}{*}{ Health cure } & Agree & 9.1 & 9.5 & 17.6 & 18.6 & 9.1 & {$[3.2 ; 15.0]$} \\
\hline & Undecided & 18.0 & 16.1 & 31.7 & 29.0 & 12.9 & {$[-0.4 ; 26.1]$} \\
\hline & Disagree & 53.4 & 56.3 & 37.6 & 40.3 & -16.0 & {$[-24.9 ;-7.1]$} \\
\hline & Don't know & 19.5 & 18.1 & 13.0 & 12.1 & -6.0 & {$[-7.3 ;-4.7]$} \\
\hline \multirow{4}{*}{ Confidant } & Agree & 59.9 & 58.2 & 76.7 & 75.6 & 17.4 & {$[2.5 ; 32.4]$} \\
\hline & Undecided & 22.7 & 23.4 & 15.0 & 15.5 & -7.9 & {$[-11.2 ;-4.6]$} \\
\hline & Disagree & 13.5 & 14.2 & 6.5 & 6.9 & -7.3 & {$[-9.5 ;-5.1]$} \\
\hline & Don't know & 3.9 & 4.3 & 1.8 & 1.9 & -2.4 & {$[-2.8 ;-1.8]$} \\
\hline \multirow{4}{*}{ Self-help group } & Agree & 50.2 & 50.3 & 46.2 & 46.3 & -4.0 & {$[-11.5 ; 3.5]$} \\
\hline & Undecided & 24.1 & 24.4 & 31.5 & 31.6 & 7.2 & {$[2.2 ; 12.2]$} \\
\hline & Disagree & 13.8 & 15.7 & 12.4 & 14.2 & -1.5 & {$[-6.3 ; 3.4]$} \\
\hline & Don't know & 11.9 & 9.6 & 9.9 & 7.9 & -1.7 & {$[-3.4 ;-0.1]$} \\
\hline \multirow{4}{*}{ Internet } & Agree & 7.9 & 1.8 & 9.9 & 2.3 & 0.5 & {$[-2.7 ; 3.7]$} \\
\hline & Undecided & 12.0 & 12.4 & 17.6 & 18.7 & 6.3 & {$[-45.7 ; 58.2]$} \\
\hline & Disagree & 64.0 & 71.0 & 58.2 & 65.8 & -5.2 & {$[-52.4 ; 42.1]$} \\
\hline & Don't know & 16.1 & 14.8 & 14.3 & 13.2 & -1.6 & {$[-4.6 ; 1.4]$} \\
\hline \multirow{4}{*}{ Do something against it oneself } & Agree & 29.0 & 28.6 & 49.5 & 49.6 & 21.0 & {$[13.6 ; 28.4]$} \\
\hline & Undecided & 24.5 & 23.0 & 22.6 & 21.2 & -1.8 & {$[-6.2 ; 2.6]$} \\
\hline & Disagree & 38.0 & 40.1 & 21.1 & 22.5 & -17.6 & {$[-23.7 ;-11.4]$} \\
\hline & Don't know & 8.5 & 8.4 & 6.8 & 6.6 & -1.8 & {$[-3.0 ;-0.5]$} \\
\hline
\end{tabular}

between schizophrenia and major depressive disorder: on one hand schizophrenia as an illness with a strong biological component, demanding psychiatric treatment, on the other hand major depression which is seen mainly as a consequence of the exposure to psychosocial stress, benefitting also from alternative treatments. In 2011, a similar survey had been conducted in Germany, using the same interview [12]. Since the 
Table 5 Treatment recommendations for schizophrenia and major depression

\begin{tabular}{|c|c|c|c|c|c|c|c|}
\hline & & \multicolumn{2}{|c|}{ Schizophrenia } & \multicolumn{2}{|c|}{ Major depression } & \multirow[b]{2}{*}{ Change } & \multirow[b]{2}{*}{$95 \% \mathrm{Cl}$} \\
\hline & & Raw \% & Adj. \% & Raw \% & Adj. \% & & \\
\hline \multirow{4}{*}{ Psychotherapy } & Agree & 79.2 & 82.7 & 69.9 & 74.6 & -8.1 & {$[-21.6 ; 5.3]$} \\
\hline & Undecided & 11.3 & 11.8 & 18.7 & 20.1 & 8.3 & {$[5.9 ; 10.6]$} \\
\hline & Disagree & 5.2 & 1.4 & 8.0 & 2.1 & 0.7 & {$[-0.7 ; 2.2]$} \\
\hline & Don't know & 4.3 & 4.1 & 3.4 & 3.3 & -0.8 & {$[-7.2 ; 5.5]$} \\
\hline \multirow{4}{*}{ Psychotropic medication } & Agree & 37.1 & 37.0 & 20.5 & 20.5 & -16.5 & {$[-22.5 ;-10.6]$} \\
\hline & Undecided & 20.6 & 20.6 & 21.5 & 21.5 & 0.9 & {$[-4.2 ; 6.0]$} \\
\hline & Disagree & 32.7 & 32.5 & 47.9 & 47.5 & 15.0 & {$[8.1 ; 21.9]$} \\
\hline & Don't know & 9.6 & 9.8 & 10.1 & 10.5 & 0.7 & {$[-0.2 ; 1.6]$} \\
\hline \multirow{4}{*}{ Relaxation techniques } & Agree & 29.4 & 29.3 & 38.7 & 39.1 & 9.8 & {$[3.5 ; 16.1]$} \\
\hline & Undecided & 27.7 & 27.1 & 29.8 & 29.1 & 2.0 & {$[-3.6 ; 7.7]$} \\
\hline & Disagree & 29.0 & 31.6 & 19.2 & 21.1 & -10.5 & {$[-16.4 ;-4.5]$} \\
\hline & Don't know & 13.9 & 12.0 & 12.3 & 10.6 & -1.4 & {$[-1.9 ;-0.8]$} \\
\hline \multirow{4}{*}{ Meditation/Yoga } & Agree & 31.7 & 32.1 & 42.2 & 42.9 & 10.8 & {$[3.9 ; 17.6]$} \\
\hline & Undecided & 29.9 & 28.7 & 30.6 & 29.4 & 0.7 & {$[-4.6 ; 5.9]$} \\
\hline & Disagree & 28.3 & 30.3 & 20.8 & 22.3 & -8.0 & {$[-13.3 ;-2.8]$} \\
\hline & Don't know & 10.1 & 8.8 & 6.4 & 5.5 & -3.3 & {$[-4.8 ;-1.9]$} \\
\hline \multirow{4}{*}{ Natural remedies } & Agree & 22.4 & 21.4 & 40.9 & 40.6 & 19.2 & {$[12.6 ; 25.8]$} \\
\hline & Undecided & 23.5 & 21.4 & 29.7 & 27.8 & 6.4 & {$[1.1 ; 11.6]$} \\
\hline & Disagree & 43.1 & 45.5 & 22.8 & 24.4 & -21.1 & {$[-27.5 ;-14.6]$} \\
\hline & Don't know & 11.0 & 11.7 & 6.6 & 7.2 & -4.5 & {$[-5.8 ;-3.2]$} \\
\hline \multirow{4}{*}{ Acupuncture } & Agree & 20.7 & 19.5 & 32.0 & 30.9 & 11.4 & {$[3.8 ; 18.9]$} \\
\hline & Undecided & 25.8 & 24.4 & 27.6 & 26.5 & 2.1 & {$[-4.2 ; 8.4]$} \\
\hline & Disagree & 38.7 & 41.4 & 27.3 & 29.5 & -11.9 & {$[-18.5 ;-5.4]$} \\
\hline & Don't know & 14.8 & 14.7 & 13.1 & 13.2 & -1.5 & {$[-5.2 ; 2.2]$} \\
\hline
\end{tabular}

interview mode was different (in France on-line, in Germany face-to-face) a direct comparison of results for schizophrenia and depression between both studies seems problematic [19]. However, it is legitimate to examine within each study the differences between both disorders and then contrast them across studies [20]. Apart from many similarities, there were some interesting differences. The divide between both disorders regarding the endorsement of current stress as a cause was more pronounced in France than in Germany. For

Table 6 Stereotypes of schizophrenia and major depression

\begin{tabular}{|c|c|c|c|c|c|c|c|}
\hline & & \multicolumn{2}{|c|}{ Schizophrenia } & \multicolumn{2}{|c|}{ Major depression } & \multirow[b]{2}{*}{ Change } & \multirow[b]{2}{*}{$95 \% \mathrm{Cl}$} \\
\hline & & Raw \% & Adj. $\%$ & Raw \% & Adj. \% & & \\
\hline & Agree & 72.6 & 73.6 & 34.5 & 35.3 & -38.3 & {$[-42.9 ;-33.8]$} \\
\hline \multirow[t]{3}{*}{ The person is unpredictable } & Undecided & 19.3 & 18.1 & 35.1 & 33.4 & 15.3 & {$[10.9 ; 19.6]$} \\
\hline & Disagree & 8.1 & 8.3 & 30.4 & 31.3 & 23.0 & {$[-11.1 ; 57.2]$} \\
\hline & Agree & 36.1 & 38.3 & 14.5 & 15.2 & -23.1 & {$[-27.6 ;-18.6]$} \\
\hline \multirow[t]{3}{*}{ The person is dangerous } & Undecided & 32.4 & 29.2 & 23.2 & 20.8 & -8.4 & {$[-12.7 ;-4.2]$} \\
\hline & Disagree & 31.5 & 32.5 & 62.3 & 64.0 & 31.5 & {$[27.6 ; 35.5]$} \\
\hline & Agree & 6.7 & 1.2 & 8.7 & 1.6 & 0.4 & {$[-20.0 ; 20.8]$} \\
\hline \multirow[t]{3}{*}{ The person is responsible for his/her condition } & Undecided & 23.5 & 25.0 & 29.4 & 31.9 & 6.9 & {$[-5.1 ; 18.9]$} \\
\hline & Disagree & 69.8 & 73.8 & 61.9 & 66.5 & -7.3 & {$[-55.6 ; 41.0]$} \\
\hline & Agree & 7.0 & 6.1 & 7.4 & 6.4 & 0.3 & {$[-1.9 ; 2.5]$} \\
\hline \multirow[t]{2}{*}{ Even with treatment, the person's state will not change significantly } & Undecided & 23.2 & 23.7 & 22.6 & 23.0 & -0.7 & {$[-4.9 ; 3.5]$} \\
\hline & Disagree & 69.8 & 70.2 & 70.0 & 70.6 & 0.4 & {$[-3.4 ; 4.2]$} \\
\hline
\end{tabular}


Table 7 Separation from persons with schizophrenia and major depression

\begin{tabular}{|c|c|c|c|c|c|c|c|}
\hline & & \multicolumn{2}{|c|}{ Schizophrenia } & \multicolumn{2}{|c|}{ Major depression } & \multirow[b]{2}{*}{ Change } & \multirow[b]{2}{*}{$95 \% \mathrm{Cl}$} \\
\hline & & Raw \% & $\overline{\text { Adj. } \%}$ & Raw \% & Adj. \% & & \\
\hline \multirow{3}{*}{ This person is different from others } & Agree & 38.2 & 32.8 & 13.0 & 10.3 & -22.5 & {$[-27.0 ;-18.1]$} \\
\hline & Undecided & 33.1 & 35.3 & 23.1 & 22.6 & -12.7 & {$[-17.5 ;-7.8]$} \\
\hline & Disagree & 28.6 & 31.9 & 63.9 & 67.1 & 35.2 & {$[31.3 ; 39.1]$} \\
\hline \multirow{3}{*}{$\begin{array}{l}\text { Basically we are all sometimes like this person. } \\
\text { It's just a question how pronounced this state is }\end{array}$} & Agree & 28.5 & 29.7 & 58.2 & 59.1 & 29.4 & {$[24.7 ; 34.2]$} \\
\hline & Undecided & 29.5 & 30.6 & 26.9 & 27.1 & -3.5 & {$[-8.1 ; 1.2]$} \\
\hline & Disagree & 42.0 & 39.8 & 14.9 & 13.7 & -26.1 & {$[-28.8 ;-23.2]$} \\
\hline
\end{tabular}

instance, in France work-related stress was seen as a cause of depression by $80 \%$ and as a cause of schizophrenia by only $47 \%$, while in Germany the respective percentages were $79 \%$ and $62 \%$; thus, the difference between both disorders was larger in France than in Germany. Moreover, the difference between both disorders in relying on self-help was more pronounced in France (depression 50\%, schizophrenia 29\%) than in Germany (depression 59\%, schizophrenia 47\%). Finally, while in France 'alternative' methods like natural remedies or acupuncture were more frequently recommended for the treatment of depression $(41 \%$ and $32 \%$,

Table 8 Emotional reactions to persons with schizophrenia or major depression

\begin{tabular}{|c|c|c|c|c|c|c|c|}
\hline & & Schizop & & Major d & sion & & \\
\hline & & Raw \% & Adj. \% & Raw \% & Adj. \% & Change & $95 \% \mathrm{Cl}$ \\
\hline & Agree & 72.1 & 74.3 & 80.9 & 82.5 & 8.2 & {$[4.1 ; 12.4]$} \\
\hline I feel the need to help him/her & Undecided & 22.4 & 24.5 & 15.6 & 16.7 & -7.8 & {$[-11.9 ;-3.7]$} \\
\hline & Disagree & 5.5 & 1.2 & 3.5 & 0.8 & -0.4 & NA \\
\hline & Agree & 70.9 & 70.9 & 79.1 & 79.5 & 8.6 & {$[4.3 ; 12.9]$} \\
\hline I feel pity for him/her & Undecided & 19.4 & 19.1 & 16.1 & 15.7 & -3.4 & {$[-7.1 ; 0.3]$} \\
\hline & Disagree & 9.7 & 10.0 & 4.8 & 4.8 & -5.2 & {$[-11.4 ; 1.0]$} \\
\hline & Agree & 46.4 & 46.4 & 69.5 & 69.9 & 23.5 & {$[18.8 ; 28.3]$} \\
\hline I feel sympathy for him/her & Undecided & 38.2 & 37.6 & 23.5 & 22.9 & -14.7 & {$[-19.2 ;-10.1]$} \\
\hline & Disagree & 15.4 & 16.0 & 7.0 & 7.2 & -8.8 & {$[-15.2 ;-2.5]$} \\
\hline & Agree & 57.9 & 59.7 & 35.2 & 36.8 & -22.9 & {$[-27.7 ;-18.0]$} \\
\hline I feel uncomfortable & Undecided & 23.5 & 22.6 & 25.8 & 25.2 & 2.6 & {$[-1.6 ; 6.8]$} \\
\hline & Disagree & 18.6 & 17.7 & 39.0 & 37.9 & 20.2 & {$[13.9 ; 26.5]$} \\
\hline & Agree & 48.0 & 49.1 & 29.4 & 30.6 & -18.5 & {$[-23.3 ;-13.7]$} \\
\hline He/she makes me feel insecure & Undecided & 25.5 & 26.5 & 28.9 & 30.6 & 4.1 & {$[-0.5 ; 8.6]$} \\
\hline & Disagree & 26.5 & 24.4 & 41.7 & 38.8 & 14.4 & {$[8.7 ; 20.2]$} \\
\hline & Agree & 35.4 & 35.3 & 22.6 & 22.3 & -13.0 & {$[-17.5 ;-8.5]$} \\
\hline He/she scares me & Undecided & 33.2 & 32.9 & 21.9 & 21.5 & -11.4 & {$[-15.8 ;-7.0]$} \\
\hline & Disagree & 31.4 & 31.8 & 55.5 & 56.2 & 24.4 & {$[20.3 ; 28.5]$} \\
\hline & Agree & 6.5 & 6.4 & 7.4 & 7.1 & 0.7 & {$[-1.7 ; 3.2]$} \\
\hline I feel annoyed by him/her & Undecided & 17.5 & 18.3 & 14.5 & 15.1 & -3.2 & {$[-7.0 ; 0.5]$} \\
\hline & Disagree & 76.0 & 75.3 & 78.1 & 77.8 & 2.5 & {$[-1.0 ; 5.9]$} \\
\hline & Agree & 5.1 & 3.7 & 6.1 & 4.4 & 0.7 & {$[-1.0 ; 2.3]$} \\
\hline I react angrily & Undecided & 13.3 & 12.8 & 13.4 & 12.9 & 0.1 & {$[-3.1 ; 3.4]$} \\
\hline & Disagree & 81.6 & 83.5 & 80.5 & 82.7 & -0.8 & {$[-4.0 ; 2.5]$} \\
\hline & Agree & 3.1 & 0.5 & 1.3 & 0.2 & -0.3 & {$[-17.0 ; 16.3]$} \\
\hline I am amused by something like that & Undecided & 7.8 & 6.2 & 3.1 & 2.4 & -3.8 & {$[-9.1 ; 1.5]$} \\
\hline & Disagree & 69.1 & 93.3 & 95.6 & 97.4 & 4.1 & {$[-29.7 ; 38.0]$} \\
\hline
\end{tabular}


Table 9 Desire for social distance from persons with schizophrenia and major depression

\begin{tabular}{|c|c|c|c|c|c|c|c|}
\hline & & \multicolumn{2}{|c|}{ Schizophrenia } & \multicolumn{2}{|c|}{ Major depression } & \multirow[b]{2}{*}{ Change } & \multirow[b]{2}{*}{$95 \% \mathrm{Cl}$} \\
\hline & & Raw \% & Adj. \% & Raw \% & Adj. \% & & \\
\hline & Accept & 41.7 & 38.0 & 47.6 & 43.8 & 5.8 & {$[1.0 ; 10.6]$} \\
\hline \multirow[t]{3}{*}{ Work together } & Undecided & 37.8 & 39.8 & 37.0 & 39.3 & -0.5 & {$[-5.4 ; 4.4]$} \\
\hline & Reject & 20.5 & 22.2 & 15.4 & 16.9 & -5.3 & {$[-0.7 ; 12.4]$} \\
\hline & Accept & 32.7 & 29.1 & 50.4 & 46.5 & 17.4 & {$[12.8 ; 22.1]$} \\
\hline \multirow[t]{3}{*}{ Have as neighbor } & Undecided & 40.5 & 42.1 & 36.4 & 38.9 & -3.2 & {$[-8.1 ; 1.8]$} \\
\hline & Reject & 26.8 & 28.8 & 13.2 & 14.6 & -14.2 & {$[-21.2 ;-7.2]$} \\
\hline & Accept & 25.6 & 22.2 & 39.1 & 35.2 & 13.0 & {$[8.6 ; 17.3]$} \\
\hline \multirow[t]{3}{*}{ Introduce to a friend } & Undecided & 35.5 & 36.3 & 37.9 & 39.8 & 3.5 & {$[-1.3 ; 8.4]$} \\
\hline & Reject & 38.9 & 41.5 & 23.0 & 25.0 & -16.5 & {$[-21.0 ;-12.0]$} \\
\hline & Accept & 12.2 & 10.3 & 21.1 & 18.2 & 7.9 & {$[4.5 ; 11.4]$} \\
\hline \multirow[t]{3}{*}{ Marry into family } & Undecided & 33.5 & 33.9 & 40.1 & 41.4 & 7.5 & {$[2.7 ; 12.4]$} \\
\hline & Reject & 54.3 & 55.8 & 38.8 & 40.3 & -15.5 & {$[-19.6 ;-11.4]$} \\
\hline & Accept & 11.1 & 11.0 & 18.7 & 18.6 & 7.6 & {$[4.1 ; 11.2]$} \\
\hline \multirow[t]{3}{*}{ Recommend for a job } & Undecided & 32.0 & 30.3 & 40.4 & 38.6 & 8.3 & {$[3.7 ; 13.0]$} \\
\hline & Reject & 56.9 & 58.8 & 40.9 & 42.7 & -16.1 & {$[-20.1 ;-12.0]$} \\
\hline & Accept & 11.6 & 9.9 & 22.1 & 19.6 & 9.7 & {$[6.2 ; 13.1]$} \\
\hline \multirow[t]{3}{*}{ Rent a room } & Undecided & 28.6 & 26.7 & 37.6 & 36.4 & 9.7 & {$[5.2 ; 14.3]$} \\
\hline & Reject & 59.8 & 63.4 & 40.3 & 44.0 & -19.4 & {$[-23.5 ;-15.3]$} \\
\hline & Accept & 1.7 & 1.6 & 9.5 & 9.0 & 7.4 & {$[4.8 ; 10.0]$} \\
\hline \multirow[t]{2}{*}{ Take care of children } & Undecided & 9.9 & 8.9 & 19.5 & 17.8 & 8.9 & {$[5.6 ; 12.3]$} \\
\hline & Reject & 88.4 & 89.5 & 71.0 & 73.2 & -16.3 & {$[-20.4 ;-12.2]$} \\
\hline
\end{tabular}

respectively) than for the treatment of schizophrenia ( $22 \%$ and $21 \%$, respectively), in Germany practically no difference was found between both disorders $(27 \% / 24 \%$ and $18 \% / 17 \%$ ) [12]. All these results suggest that the distinction made between schizophrenia and depression tends to be more marked in France than in Germany.

Irrespectively of the type of disorder, psychotherapy was the clear favorite. The acceptance of it was even more pronounced regarding the treatment of schizophrenia, which appears somewhat counterintuitive. This is not a French specialty. In the afore-mentioned German survey, $73 \%$ of respondents recommended psychotherapy for the treatment of depression and $84 \%$ for the treatment of schizophrenia. Similar findings have also been reported from previous studies (e.g. [21-23]). The public's reservation against psychotropic medication has also been observed in Germany. However, the contrast to the acceptance of psychotherapy was not as marked there as in France. For instance concerning the treatment of schizophrenia, $79 \%$ of respondents opted in France for psychotherapy and only 37\% for medication, whereas in Germany the corresponding figures were $84 \%$ and $51 \%$. A similar pattern was also found for depression $(70 \% / 21 \%$ versus $73 \% / 36 \%)$. Interestingly, the difference between both countries in attitudes does not correspond with the actual use of psychotropic medication which is higher in France than in Germany [24]. The reasons for the aversion against psychotropic medication expressed by the French public are certainly manifold. One may be that while in both countries current stress was in sum more frequently endorsed than biogenetic causes, the preponderance of the first was slightly more pronounced in France. Regarding depression, for instance, the ratio between the sum of stress factors and the sum of biogenetic causes was twice as high in France as in Germany. Another reason may be that medication still tends to be seen by the public less as treatment of the real causes of an illness than psychotherapy, particularly psychoanalysis, which in France still enjoys relatively great popularity [25]. Finally, the widespread fear of getting addicted to medication may play a role, as the public is not able to sufficiently distinguish between drugs that have this unwanted effect, such as benzodiazepines, and others, such as antidepressants or antipsychotics, which do not have it [26].

\section{Attitudes towards people with schizophrenia and major depressive disorder}

Across all components studied, attitudes towards people with schizophrenia were more unfavorable than those 
towards people with major depressive disorder. People with schizophrenia more frequently were perceived as unpredictable and dangerous, there was a stronger need to separate 'us' from 'them', they were more frequently met with fear and less frequently reacted to with prosocial feelings, and they faced more rejection. As with beliefs, the comparison with the German survey yields some interesting differences. For instance, concerning the endorsement of dangerousness, the discrepancy between both disorders was greater in France than in Germany (ratio schizophrenia/major depression in France $36 \% / 14 \%$, in Germany $23 \% / 19 \%$ ). While in France, $28 \%$ of respondents agreed with the statement that 'we are all sometimes like this person' in case of schizophrenia and $58 \%$ in case of major depression, in Germany, the difference between both disorders was smaller with $26 \%$ and $44 \%$, respectively. While the difference between schizophrenia and major depression in the amount of fear expressed by respondents was in both countries the same, the difference in pro-social feelings in favor of major depression was more marked in France. Taken together, the discrepancy between attitudes towards people suffering from schizophrenia and major depressive disorder appears to be slightly more pronounced in France than in Germany. As already observed with illness beliefs [6], French people seem to distinguish between both disorders even more clearly than their German counterparts. While depression is perceived as something most people are familiar with through personal experience and as something which more or less belongs to normal life, people with schizophrenia are perceived as strange (by $60 \%$ of respondents as compared to only $16 \%$ with depression) and their behavior appears as incomprehensible (45\% versus $21 \%$ ). Another indication of the great familiarity of the French people with the notion of depression may be that almost all respondents (88\%) identified the depressive symptoms depicted in the vignette as an expression of some sort of depression [27].

\section{Limitations}

Before concluding, some limitations of our study should be mentioned. First, the focus on attitudes may be looked upon as a limitation since it allows predicting behavior with less than ideal accuracy. However, rather than using them as a proxy for individual behaviors, public attitudes can also be conceptualized at a collective level as a reflection of cultural conceptions of mental illness. Such conceptions form a cultural context that influences the way we behave towards those suffering from mental illness. As Link et al. [28] have pointed out, 'as a context this cultural conception becomes an external reality, something that individuals must take into account when they make decisions and enact behavior' (p. 255). Second, due to selection processes typical for on-line surveys [19], the representativeness of the results for the whole of the French population may be considered uncertain. In this context it seems worth noting that the feasibility of this interview mode for exploring beliefs and attitudes about mental disorders has recently been shown in another survey in France [29]. Third, social desirability may have biased our findings in the sense that respondents may have responded to interview questions in a way that makes them appear socially desirable, and may not actually have responded according to their true reactions. However, this seems to be less a problem in online interviews than in face-to-face interviews [30]. Finally, we do not know how the terms used in the interview were understood by the respondents. For instance, what the lay public associates with this term 'psychotherapy' does not necessarily reflect how psychotherapy is defined by mental health professionals. A recently published study comes to the conclusion that lay people appear to have 'a modestly realistic but somewhat naive view of the process and efficacy of psychotherapy' [31]. It is not unlikely that many people simply associate with psychotherapy talking with patients [32].

\section{Conclusions}

In conclusion, we can state that there is a strong tendency among the French public to make a distinction between schizophrenia and major depression concerning illness beliefs. Thus, despite theoretical and methodological differences, our results converge with those reported by Roelandt et al. [1,2]. What they found exploring the social representations of mundane labels for mental illness ('insane', 'depressive') resonates in our findings based on descriptions of schizophrenia and major depressive disorder as they are defined by modern psychiatric diagnostic classifications. This applies equally to beliefs about these illnesses (e.g., their causes or treatment) as to attitudes towards persons suffering from them. There is a need for interventions trying to reduce existing misconceptions in order to improve the care of patients.

\section{Competing interests}

All authors have no competing interests to declare.

\section{Authors' contributions}

MCA developed the interview and drafted the manuscript. AM and CR were involved in the translation of the interview and helped coordinate the survey. AM and TR performed the statistical analyses. MT conceived of the study, organized the survey, and helped draft the manuscript. All authors read and approved the final manuscript.

\section{Author details}

${ }^{1}$ Center for Public Mental Health, Gösing am Wagram, Austria. ${ }^{2}$ Department of Public Health and Clinical and Molecular Medicine, University of Cagliari, Cagliari, Italy. ${ }^{3}$ Creativ-Ceutical, Paris, France. ${ }^{4}$ Creativ-Ceutical, Tunis, Tunisia. ${ }^{5}$ University of Lyon I, Lyon, France.

Received: 25 January 2013 Accepted: 18 November 2013 Published: 20 November 2013 


\section{References}

1. Roelandt J-L, Caria A, Defromont L, Vandeborre A, Daumerie N: Représentations sociales du "fou', du "malade mental' et du "dépressif' en population génerale en France [Representations of insanity, mental illness and depression among the general population in France]. Encéphale 2010, 36:7-13.

2. Roelandt J-L, Caria A, Benradia I, Defromont L: Perceptions sociales du 'fou', du 'malade mental' et du 'dépressif' en population générale en France [Social perceptions of the 'insane', the 'mentally ill' and the 'depressive' among the general population in France]. In La stigmatization en psychiatrie et en santé mentale. Edited by Giordana J-Y. Paris: Elsevier Masson; 2010:47-69.

3. Angermeyer MC, Dietrich S: Public beliefs and attitudes towards people with mental illness: a review of population studies. Acta Psychiatr Scand 2006, 113:163-179

4. Angermeyer MC, Matschinger $\mathrm{H}$ : Public beliefs about schizophrenia and depression: similarities and differences. Soc Psychiatry Psychiatr Epidemiol 2003, 38:526-534.

5. Jorm AF, Oh E: Desire for social distance from people with mental disorders: a review. Austr N Z J Psychiatry 2009, 43:183-200

6. Jorm A: Mental health literacy: public knowledge and beliefs about mental disorders. Br J Psychiatry 2000, 177:396-402.

7. Jorm AF, Korten AE, Jacomb PA, Christensen H, Rodgers B, Pollitt P: 'Mental health literacy': a survey of the public's ability to recognize mental disorders and their beliefs about the effectiveness of treatment. Med J Aust 1997, 166:182-186.

8. Schomerus G, Matschinger $\mathrm{H}$, Angermeyer MC: Determinants of intention to seek psychiatric help for depression: a representative population survey applying the theory of planned behaviour. Psychol Med 2009, 39:1855-1865

9. Link BG, Phelan JC: Conceptualizing stigma. Ann Rev Sociol 2001, 27:363-385.

10. Link BG, Yang LH, Phelan JC, Collins PY: Measuring mental illness stigma. Schizophr Bull 2004, 30:511-541.

11. Institut national de la statistique et des études économiques. www.insee.fr.

12. Angermeyer MC, Matschinger $\mathrm{H}$, Schomerus $\mathrm{G}$ : Attitudes towards psychiatric treatment and people with mental illness: changes over two decades. Br J Psychiatry 2013, 203:146-151.

13. Sartorius N, Kuyken J: Translation of health status instruments. In Quality of life assessment in health care settings: volume 1. Edited by Orley J, Kuyken J. Berlin: Springer-Verlag; 1994.

14. American Psychiatric Association: Diagnostic and statistical manual of mental disorders: 3rd edition - revised. Washington, D.C: American Psychiatric Association; 1987.

15. Hayward P, Bright JA: Stigma and mental illness: a review and critique. J Ment Health 1997, 6:345-354.

16. Angermeyer MC, Matschinger $\mathrm{H}$ : The stigma of mental illness: effects of labeling on public attitudes towards people with mental disorder. Acta Psychiatr Scand 2003, 108:304-309.

17. Link BG, Cullen FT, Frank J, Wozniak JF: The social rejection of former mental patients: understanding why labels matter. Am I Sociol 1987, 92:1461-1500.

18. http://www.sas.com/offices/europe/france/.

19. De Leeuw ED, Hox JJ, Dillman DA: International handbook of survey methodology. New York, London: Psychology Press; 2008.

20. Fryers $T$, Melzer $D$, Jenkins $R$, Brugha $T$ : The distribution of the common mental disorders: social inequalities in Europe. Clin Pract Epidemiol Ment Health 2005, 1:14.

21. Angermeyer MC, Matschinger $\mathrm{H}$ : Public attitudes towards psychiatric treatment. Acta Psychiatry Scand 1996, 94:326-336.

22. Lauber C, Nordt C, Falcato L, Rössler W: Lay recommendations on how to treat mental disorders. Soc Psychiatry Psychiatr Epidemiol 2011, 36:553-556.

23. Angermeyer MC, Holzinger $\mathrm{A}$, Matschinger $\mathrm{H}$ : Mental health literacy and attitude toward people with mental illness: a trend analysis based on population surveys in the eastern part of Germany. Eur Psychiatry 2009, 24:225-232.

24. Alonso J, Angermeyer MC, Bernert S, Bruffaerts R, Brugha TS, Bryson H, de Girolamo G, de Graaf R, Demyttenaere K, Gasquet I, Haro JM, Katz S, Kessler RC, Kovess V, Lépine JP, Ormel J, Polidori G, Vilagut G: Psychotropic drug utilization in Europe: results from the European study of epidemiology of mental disorders (ESEMeD) project. Acta Psychiatr Scand 2004, 109(420):55-64.

25. Verdoux H: Psychiatry in France. Int I Soc Psychiatry 2003, 49:83-86.

26. Angermeyer MC, Held T, Görtler D: Pro and contra: psychotherapie und psychopharnakotherapie im urteil der bevölkerung [Pro and cons: psychotherapy and psychopharmacological treatment as seen by the public]. Psychother Psychosom Med Psychol 1993, 43:286-292.
27. Angermeyer MC, Schomerus G, Carta MG, Moro MF, Toumi M, Millier A, Holzinger A: Burnout: Ein deutsches phänomen? [Burnout: a German phenomenon?]. Psychiat Prax 2013, 40:425-429.

28. Link BG, Angermeyer MC, Phelan JC: Public attitudes towards people with mental illness. In Oxford textbook of community mental health. Edited by Thornicroft G, Szmukler G, Mueser KT, Drake RE. Oxford: Oxford University Press; 2011:253-259.

29. Durand-Zaleski I, Scott I, Rouillon F, Leboyer M: A first national survey of knowledge, attitudes and behaviours towards schizophrenia, bipolar disorders and autism in France. BMC Psychiatry 2012, 12:128.

30. Henderson C, Evans-Lacko S, Flach C, Thornicroft G: Responses to mental health stigma questions: the importance of social desirability and data collection method. Can J Psychiatry 2012, 57:152-160.

31. Furnham A: Psychiatric and psychotherapeutic literacy: attitudes to, and knowledge of, psychotherapy. Int J Soc Psychiatry 2009, 55:525-537.

32. Holzinger $A$, Matschinger $H$, Drexler $V$, Angermeyer MC: 'Was denken Sie was ein psychiater macht?...Und was denken Sie macht ein psychotherapeut?' ergebnisse einer repräsentativerhebung bei der wiener bevölkerung [ ${ }_{\text {, }}$ what do you think a psychiatrist's work is like ... and what about a psychotherapist?' results of a survey among the citizens of Vienna]. Psychiat Prax 2010, 37:329-334.

\section{doi:10.1186/1471-244X-13-313}

Cite this article as: Angermeyer et al: Attitudes and beliefs of the French public about schizophrenia and major depression: results from a vignette-based population survey. BMC Psychiatry 2013 13:313.

\section{Submit your next manuscript to BioMed Central and take full advantage of:}

- Convenient online submission

- Thorough peer review

- No space constraints or color figure charges

- Immediate publication on acceptance

- Inclusion in PubMed, CAS, Scopus and Google Scholar

- Research which is freely available for redistribution
() Biomed Central 